\begin{tabular}{l} 
References \\
\hline 1. Woolf SH. Practice guidelines: a new reality in \\
medicine, I: recent developments. Arch Intern \\
Med 1990;150:1811-8. \\
2. Woolf SH. Practice guidelines: a new reality in \\
medicine, II: methods of developing guidelines. \\
Arch Intern Med 1992;152:946-52. \\
3. Woolf SH. Practice guidelines: a new reality in \\
medicine, III: impact on patient care. Arch Intern \\
Med 1993;153:2646-55. \\
4. Broshy E, Matheson D, Hansen M. Want to \\
curb health costs? Manage the disease, not each \\
cost component. Med Market Media 1993:76-83. \\
5. The changing environment for U.S. pharma- \\
ceuticals: the role of pharmaceutical companies in \\
a systems approach to healthcare. Boston, Mass: \\
The Boston Consulting Group Inc., 1993. \\
6. Levy R. A systems approach to cost manage- \\
ment. Drug Benefits Trends 1994;6(1):4-8.
\end{tabular}

7. Dearing G. Disease management: a backgrounder for Eli Lilly and Company. San Francisco: The Zitter Group, 1994(Oct)

8. Zalta E. The resource-based relative value scale: a model for the private sector. Med Interface 1992:5(2):19-44.

9. Soumerai SB, Ross-Degnan D, Avorn J, et al. Effects of Medicaid drug-payment limits on admission to hospitals and nursing homes. N Engl J Med 1991;325:1072-7.

10. Zitter $M$. The Genesis Report $(/ M C x$ 1995(Feb); 1(3): 12-3.

11. Mittman R. Outcomes and disease management-their role in the future of healthcare. Presentation at Outcomes and Disease Management. San Francisco: 1994(Dec).

12. US Congress, Office of Technology Assessment. Identifying health technologies that work: searching for evidence. OTA-H-608. Washington, D.C.: US Government Printing Office, 1994(Sep). 13. Segedin DA. Strategies to incorporate a successful clecision-support systcm. Presentation at Outcomes and Disease Management. San Francisco: 1994(Dec).

14. Zitter M. Disease management: a systems approach to managing health outcomes. Med interface 1995(Jan); 1(8):70-90

15. Muirhead G. The ABCs of PBMs. Drug Topic 1994(Sept5): 67-79

16. Macken $\mathrm{C}$. Managing disease management. Prod Manage Today 1994(Sept): 28-9.

\title{
The Evolution of Disease State Management: Historical Milestones and Future Directions
}

\author{
Laetitia A. N'Dri, PharmD; Seojin Park, PharmD; and David B. Nash, MD, MBA
}

\section{SUMMARY}

Twenty-five years ago, the Journal of Managed Care Pharmacy introduced its readers to disease state management, which attempted to break the siloed culture of the U.S. health care system. Disease state management has been transformed, in part, to population health management. This shift was marked by 3

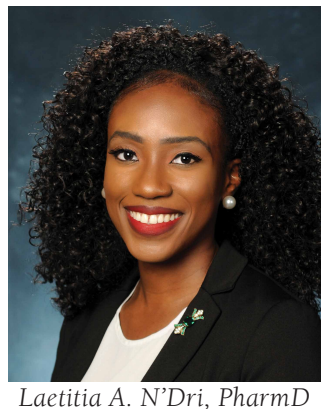

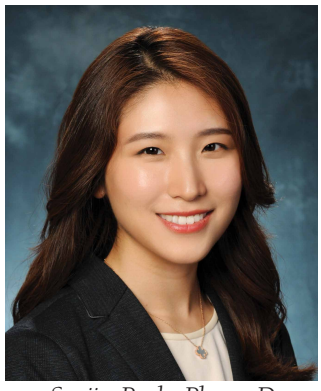

Seojin Park, PharmD

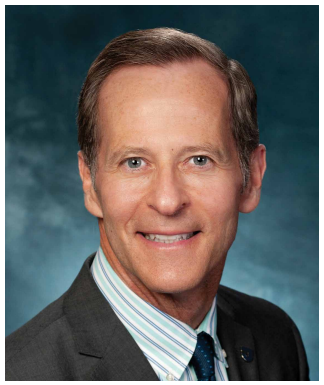

David B. Nash, MD, MBA wenty-five years
ago, disease state
manage men $\mathrm{t}$ sought to improve patient outcomes by maximizing the interrelationship between physicians, payers, pharmaceutical companies, main inflection points: the rise of the web-enabled smartphone, the Patient Protection and Affordable Care Act (ACA), and the adoption of artificial intelligence (Al). The introduction of smartphones filled the communication gap through improved patient engagement and accessible mobile applications, giving patients access to their clinical data. In addition, through the ACA, bundled payment models moved away from a volume-based to a value-based payment approach and attempted to incorporate population health concerns, such as the social determinants of health. The advancement of Al will allow the health care system to collect comprehensive health data and to predict the population at higher risk. Despite these advancements, some challenges from 25 years ago remain, yet rapid technology advancements may expedite the next wave of change.

J Manag Care Spec Pharm. 2020;26(2):90-93

Copyright $\odot 2020$, Academy of Managed Care Pharmacy. All rights reserved. pharmacists, and patients to manage chronic conditions. On the 25th anniversary of the Journal of Managed Care \& Specialty Pharmacy, in which Hadsall and Sargent (1995) first introduced the concept of disease state management to readers, ${ }^{1}$ we reflect on the evolution of disease state management. We also address 3 key inflection points-the rise of the web-enabled smartphone, the Patient Protection and Affordable Care Act (ACA), and artificial intelligence (AI) — that have collectively transitioned disease state management to population health management. 


\section{Historical Evolution}

\section{Disease State and Care Management Models}

Before 1995, practice guidelines were introduced to promote uniformity of care. ${ }^{2}$ However, the guidelines largely failed to earn support from physicians, who regarded them as "cookbook" medicine that eliminated the role of clinical judgement. In addition, without appropriate financial incentives, guidelines could have meant decreasing the volume of services that were perceived as needed. Despite the initial resistance of physicians toward practice guidelines, ${ }^{3}$ disease state management, which heavily relied on them, emerged in 1995.

The rise of disease state management stemmed from the cost pressures on managed care organizations. ${ }^{4-6}$ Although shortterm savings were observed, long-term projections of such programs remained unclear. The early stage of this system favored relatively low-risk patients, while individuals with complex and costly health conditions were assigned to specialized companies. Although unintended, these specialized interventions added to the fragmentation of care. ${ }^{6}$ The initial challenges of disease state management were reluctance from physicians, patient retention, and the pharmaceutical companies as early adopters (which was perceived as a marketing strategy). ${ }^{4}$ In retrospect, disease state management might have succeeded in managing patients with relatively expensive, but manageable chronic conditions. However, the lack of transparency between physicians and managed care organizations hindered this process. ${ }^{7}$

In an attempt to unify health care delivery, payers introduced care management programs for complex patients in the outpatient setting. ${ }^{89}$ Care management has been shown to increase communication between physicians and patients, to use evidence-based care, and to enhance adherence. ${ }^{9}$ It included the following core competencies: data integration, patient stratification, care coordination, patient engagement, and performance measurement. ${ }^{8-10}$ Some observers believed that the success of care management as compared with disease state management was a result of its ability to use technology to identify patients. ${ }^{11}$

\section{From Disease Management to Population Health Management}

Population health is defined as "the distribution of health outcomes within a population, the determinants that influence distribution, and the policies and interventions that affect the determinants." 12 Compared with disease state management, population health management attempted to look beyond the rudimentary clinical picture to capture health outcomes at the population level. This comprehensive approach was shaped by the following inflection points: the web-enabled smartphone, the ACA, and AI.

\section{The Rise of the Web-Enabled Smartphone}

The lack of patient engagement was one of the early pitfalls of disease state management. The smartphone was an easy and inexpensive solution to reach patients as most Americans began to own them. By 2010, there were 5,805 health-related mobile applications, with $3 \%$ of them pertaining to chronic diseases. ${ }^{13}$ Concurrently, there was an increase in the use of electronic health record (EHR) systems, supported by the Health Information Technology for Economic and Clinical Health Act of 2009. ${ }^{14}$ A national survey from the Centers for Disease Control and Prevention showed that the use of any EHR system increased from $18.2 \%$ in 2001 to $50.7 \%$ in $2010 .{ }^{15}$ Such expansion allowed physicians to record clinical information electronically and patients to access their own health data remotely. Although access to smartphone data based on socioeconomic and health status are potential barriers, the smartphone is a promising step toward a unified health care system. ${ }^{16,17}$

The smartphone has revolutionized disease state management by creating a secure and open stream of shared information at a relatively low cost for patients and physicians. At the same time, advanced EHR systems, which included comprehensive health data, helped to change disease state management to population health management.

\section{The Affordable Care Act}

In 2010, the passage of the ACA boosted population health management through the expansion of health care coverage, improvement of quality of care, prevention and health promotion, and community-based programs. ${ }^{18}$ Specifically, it focused on improving the quality and efficiency of care through the Centers for Medicare \& Medicaid Services innovations models. ${ }^{19}$ The bundled payment system was created to move away from traditional fee for service and instead to test whether a system focused on episodes of care could decrease health care expenditures. This directly addressed one of the impediments to disease state management success: lack of a financial incentive structure. However, as in disease state management, defining an episode of care for a chronic condition remains a challenge. To address this limitation, bundled payment models are beginning to take a wider view by incorporating population health concerns such as comorbidities and social determinants of health.

\section{Artificial Intelligence}

Despite the advancement of the current EHR analytical capabilities, most still lack the power to extract clinical information. Yet, as health care evolves toward a comprehensive data-driven environment, AI can maximize our ability to collect information from unstructured narrative texts, such as clinical notes. Natural language processing turns the texts to machinereadable data, which then can be analyzed to supplement and 
enrich the medical records. ${ }^{20}$ With comprehensive health data and the predictive power of AI, risk prediction can further improve current population health management. Risk predictive algorithms used at the population level can support decision making for chronic disease prevention. ${ }^{21}$ The capability of AI to provide high-resolution clinical data and sharing such data in a collaborative clinical practice environment has the potential to advance efficient and high-quality care. However, leadership from policymakers and engagement of all health care stakeholders is needed for widespread adoption of $\mathrm{AI}^{2}{ }^{22}$

\section{Conclusions}

Disease state management transformed into population health management around 3 main inflection points: the introduction of the web-enabled smartphone, the ACA, and the adoption of AI. In the last 25 years, this movement progressed into a comprehensive and data-driven approach to care for patients with complex and chronic diseases. Regrettably, some of the health care issues identified 25 years ago persist today, such as system fragmentation and the lack of data transparency. Despite the advances seen in the health care system, the transition from disease state management to population health is not yet complete. Yet, rapidly changing technology suggests that changes to improve patient outcomes may occur faster than in the past.

\section{Authors}

LAETITIA A. N'DRI, PharmD, and SEOJIN PARK, PharmD, Health Economics \& Outcomes Research (HEOR) Fellows, Jefferson College of Population Health, Philadelphia, Pennsylvania. DAVID B. NASH, MD, MBA, Founding Dean Emeritus, Jefferson College of Population Health, Philadelphia, Pennsylvania.

AUTHOR CORRESPONDENCE: David Nash, MD, MBA, Jefferson College of Population Health, 901 Walnut St., 10th Fl., Philadelphia, PA 19107. E-mail: David.Nash@jefferson.edu.

\section{DISCLOSURES}

No funding contributed to the writing of this article. The authors have nothing to disclose with respect to research, authorship, and/or publication of this article.

\section{REFERENCES}

1. Hadsall RS, Sargent LJ. Disease state management. J Manag Care Pharm. 1995;1(2):128-33. Available at: https://www.jmcp.org/doi/pdf/10.18553/ jmcp.1995.1.2.128. Accessed December 29, 2019.

2. Woolf SH. Practice guidelines: a new reality in medicine. III. Impact on patient care. Arch Intern Med. 1993;153(23):2646-55. Available at: https:// jamanetwork.com/journals/jamainternalmedicine/fullarticle/618145. Accessed December 29, 2019.
3. Woolf SH. Practice guidelines: a new reality in medicine. II. Methods of developing guidelines. Arch Intern Med. 1992;152(5):946-52. Available at: https://jamanetwork.com/journals/jamainternalmedicine/fullarticle/616225. Accessed December 29, 2019.

4. Harris JM Jr. Disease management: new wine in new bottles? Ann Intern Med. 1996;124(9):838-42. Available at: https://www.annals.org/aim/fullarticle/doi/10.7326/0003-4819-124-9-199605010-00009. Accessed December 29, 2019.

5. Todd WE, Nash D. Disease Management: A Systems Approach to Improving Patient Outcomes. Chicago, IL: American Hospital Publishing; 1997.

6. Bodenheimer T. Disease management-promises and pitfalls. N Engl J Med. 1999;340(15):1202-05. Available at: https://www.nejm.org/doi/ pdf/10.1056/NEJM199904153401511. Accessed December 29, 2019

7. Winn P. The role of physicians in disease management. Managed Care. October 1, 1996. Available at: https://www.managedcaremag.com/archives/1996/ 10/role-physicians-disease-management. Accessed December 29, 2019.

8. Libersky J, Au M, Hamblin A. Using lessons from disease management and care management in building integrated care programs. Integrated Care Resource Center Technical Assistance Brief. April 2014. Available at: https://www.integratedcareresourcecenter.com/sites/default/files/ICRC_ Disease_Management_and_CareCoordination_Brief_4-15-14.pdf. Accessed December 29, 2019

9. Agency for Healthcare Research and Quality (AHRQ). Care management: implications for medical practice, health policy, and health services research. August 2018. Available at: https://www.ahrq.gov/ncepcr/care/coordination/mgmt.html\#vehicle. Accessed December 29, 2019.

10. Staheli R. The 3 must-have qualities of a care management system. Health Catalyst. 2018. Available at: https://downloads.healthcatalyst.com/ wp-content/uploads/2017/02/3-must-have-qualities-of-a-care-managementsystem_white-paper.pdf. Accessed December 29, 2019

11. Alliance of Community Health Plans (ACHP). Health plan innovations in patient-centered care: care management. 2011. Available at: https://www. achp.org/wp-content/uploads/ACHP-Care-Management-Handbook.pdf. Accessed December 29, 2019.

12. Nash D, Fabius R, Skoufalos A, Clarke J, Horowitz M. Population Health: Creating a Culture of Wellness. 2d ed. Burlington, MA: Jones \& Bartlett Publishers; 2016.

13. Sarasohn-Kahn J. How smartphones are changing health care for consumers and providers. California Healthcare Foundation. April 2010. Available at: https://www.chcf.org/wp-content/uploads/2017/12/PDFHowSmartphonesChangingHealthCare.pdf. Accessed December 29, 2019.

14. HealthIT.gov. Health IT legislation. Available at: https://www.healthit.gov/topic/laws-regulation-and-policy/health-it-legislation. Accessed December 29, 2019.

15. Hsiao CJ, Hing E, Socey TC, Cai B. Electronic medical record/electronic health record systems of office-based physicians: United States, 2009 and preliminary 2010 state estimates. Centers for Disease Control and Prevention. December 2010. Available at: https://www.healthit.gov/ sites/default/files/pdf/emr-ehr-office-based-physicians-2009.pdf. Accessed December 29, 2019

16. Valle J, Godby T, Paul DP 3rd, Smith H, Coustasse A. Use of smartphones for clinical and medical education. Health Care Manag (Frederick). 2017;36(3):293-300.

17. Leijdekkers P, Gay V. User adoption of mobile apps for chronic disease management: a case study based on myFitnessCompanion ${ }^{\circledR}$. In: Donnelly M, Paggetti C, Nugent C, Mokhtari M. eds. Impact Analysis of Solutions for Chronic Disease Prevention and Management. ICOST 2012. Lecture Notes in Computer Science (7251). Berlin, Heidelberg: Springer; 2012.

18. Stoto MA. Population health in the Affordable Care Act era. Academy Health. February 21, 2013. Available at: https://www.academyhealth.org/ files/publications/files/AH2013pophealth.pdf. Accessed December 29, 2019. 
19. Centers for Medicare \& Medicaid Services (CMS). Bundled Payments for Care Improvement (BPCI) Initiative: general information. November 26, 2019. Available at: https://innovation.cms.gov/initiatives/bundled-payments/ Accessed December 29, 2019

20. Jiang F, Jiang Y, Zhi H, et. al. Artificial intelligence in healthcare: past, present and future. Stroke Vasc Neurol. 2017;2(4):230-43. Available at: https:// svn.bmj.com/content/svnbmj/2/4/230.full.pdf. Accessed December 29, 2019.
21. Population Health Analytics Laboratory. Artificial intelligence and population health. Available at: https://pophealthanalytics.com/project/artificialintelligence-and-public-health/. Accessed December 29, 2019.

22. Panch T, Szolovits P, Atun R. Artificial intelligence, machine learning and health systems. J Glob Health. 2018;8(2):020303. Available at: http://jogh.org/ documents/issue201802/jogh-08-020303.pdf. Accessed December 29, 2019. 